\title{
Preface
}

\section{GOALS OF THIS BOOK}

This book focuses on the application of law and economics to Chinese law and to the development of the economic analysis of law in China. The reason seems relatively clear: the interesting domain of law and economics has been developed within the context of the American (common and regulatory) legal system in the 1960s and 1970s and has later also been applied by many scholars in Europe to the civil law. The interesting question obviously arises as to the extent to which this expanding domain of law and economics is also suited to application to developing economies like China. There is a growing interest in law and economics in China as well, more particularly in law schools with a strong multidisciplinary background, like Fudan University, Beijing University and Shandong University. Many young Chinese lawyers and economists are aware of the wide literature in this domain and apply it in their research. However, until now there has not been a closer cooperation between European law and economics scholars and Chinese scholars in order to analyse more precisely to what extent the law and economics models that have so far been within the context of developed countries can be used for a country like China as well.

This book attempts to answer precisely that question. We therefore hope that this book may be of interest both to scholars generally interested in the economic analysis of law and to Chinese lawyers, economists and social scientists interested in developing legal institutions with an eye on economic efficiency. Traditional (European and American) law and economics scholars may benefit from applying their traditional models to Chinese law by grasping the opportunity to test traditional models in new fields, given the rich material available in China. Within the particular Chinese context of the rapidly growing economy, law and economics may be a particularly suitable instrument for examining how a legal system can be developed to meet the needs of that particular rapid development. 


\section{METHODOLOGY}

The methodology used in this book is of course the economic analysis of law. Traditional neoclassical, but also public choice models will be used to address the Chinese legal system. The book is the result of cooperation between Chinese and European law and economics scholars. However, the method chosen is not the conventional one where the European scholar is solely concerned with the analysis of his or her national (or European) legal system and the Chinese scholar deals only with Chinese law. On the contrary, the European law and economics scholars directly apply an integrated approach throughout these pages, whereby an effort is made to apply conventional models directly to Chinese law. Furthermore, the Chinese law and economics scholars use the law and economics models to address particular problems from Chinese law with an attempt to explain whether law and economics can be of any use in analysing the particular features of the Chinese legal system today. A particular challenge to which a lot of attention is paid in the book consists, of course, of the fact that many aspects of the Chinese legal system today do not correspond at all with what economists would advise as an efficient legal system. For instance, a few chapters pay a lot of attention to the fact that informal and personal relations play an important role within the Chinese (not only political but also economic) context. It is the well-known concept of 'guanxi' (literally 'relations') that explains a lot of the particular Chinese legal context. A lot of attention is obviously also paid to the fact that, differently than in the US or Europe, the state involvement in China is still spectacularly high. That has important implications, for instance, for the area of corporate law, but also for securities. To some extent, it is, methodologically, not difficult to come to the (too straightforward) conclusion that some of these traditional features of the Chinese legal system do not directly fit into the neoclassic paradigm on which the economic analysis of law is built. However, the contributors to this book do not stop with that simple conclusion but rather try to take the analysis further by analysing whether, even within this particular Chinese context (of guanxi and high state involvement), law and economics can still contribute to a better understanding of the legal system.

In that sense, the reader will also notice that many of the chapters in this volume are both of a positive and of a normative nature. Most contributors use law and economics in a positive way, to explain the particular shape of the Chinese legal system in particular areas. However, most contributors do not stop there, but also indicate how the Chinese legal system (or particular proposals, for example with respect to competition law) could be changed if the policy maker would wish to make the legal rules in those 
particular areas more in line with predictions concerning economic efficiency. Therefore, the contributions to this book are certainly not merely theoretical, but have practical and policy implications as well. The reader will notice specific analyses of, for example, the Chinese tax system, competition law, intellectual property or professional regulation in China. Every time Chinese law is confronted with predictions from the law and economics literature and some conclusions in that respect are formulated, that could be used at the policy level as well, of course, if one considers economic efficiency as a criterion for shaping legislation.

\section{TOPICS}

Of course, even though this book has the ambitious title 'Economic Analysis of Law in China', the volume does not at all attempt to provide a comprehensive economic analysis of Chinese law. This volume is a collection of essays rather than a Chinese version of Posner's well-known 'Economic Analysis of Law'. The various contributions rather focus on the validity and applicability of traditional law and economic models in the context of a country like China. Therefore, the topics chosen are not merely chosen because of their relevance from the Chinese legal perspective, but of course also from the perspective of law and economics theory. For instance, many traditional economic models may assume that an efficient enforcement of regulation can take place within the context of effective legal protection. It may thus be interesting to examine whether other and perhaps different legal rules are necessary if it appears that one cannot in all circumstances rely on an independent administrative agency, whereby civil servants merely work for the benefit of the public. Thus a particular analysis of the Chinese legal system is of interest since it can bring important insights into the consequences of opportunistic behaviour concerning the way in which legal rules should be shaped. The same is of course the case for the other examples mentioned, such as the importance of 'guanxi' within the context of the Chinese legal system, but also the high involvement of public authorities and, more particularly, the state.

Given this background, this volume has selected a number of topics within Chinese law which are centred on a variety of problem areas. A first group of chapters deals with basic features of the Chinese economic system. Unavoidably, primary attention has to be paid to the regulation of competences for law making and regulation within the Chinese context. Hence the economics of federalism has to be applied to Chinese law. Next, a fundamental issue is of course the way in which the tax system is used, 
whereby the question arises whether the taxation system in China corresponds to basic economic notions of efficient taxation. A very basic feature, as already mentioned, is the high reliance in China on informal relations and 'guanxi'. The question arises what the relevance of these social practices is for the development of an efficient legal system within the Chinese context.

A second set of contributions deals with specific aspects of the Chinese legal system from an economic perspective. These chapters take particular aspects of Chinese law and apply traditional law and economics insights to them. In that respect, attention is paid to competition policy and professional regulation, as well as to opportunistic behaviour and regulatory arrangements. In addition, law and economics of course also must be applied to the area of corporate law, financial securities and, more broadly, commercial law. Traditional economics of corporate law must thus be applied to monitoring problems in Chinese stock companies and the question also arises as to how capital markets are regulated in China, given the high-level protection awarded to so-called special treatment firms (with a high state involvement). Since China is also increasingly exposed to the virtual world, the question also arises as to how traditional economics of property rights can be applied to problems of virtual property rights as well.

The third part deals with China in the world economy. Indeed, to an important extent, regulations in China may affect China's position within the world economy. This is, for instance, the case for regulation concerning marine oil pollution, but more particularly for the important area of intellectual property law, given the specific problems that arise within the context of China in that respect.

\section{FRAMEWORK AND PARTNERS}

The book originated from cooperation between the three editors of this book, Professor Zhang Naigen, Professor of Law at Fudan University, Professor Thomas Eger, Economist at Hamburg University and Professor Michael Faure of the Maastricht European Institute for Transnational Legal Research (METRO). Professor Thomas Eger and Professor Michael Faure have a longstanding cooperation through their membership of the European Association of Law and Economics. Professor Eger and Professor Faure individually established contacts with Professor Zhang Naigen, one of the experts in law and economics in China. Within the context of the Erasmus Mundus Programme, 'European Master in Law and Economics' Professor Zhang Naigen spent several longer research 
periods at the University of Hamburg, where the project that served as the basis of this book could be prepared.

The chapters contained in this book are a selection of papers that were presented at a China-Europe conference on law and economics which was held in March 2006 at the Law School of Fudan University in Shanghai. An anonymous refereeing process was used to select the papers.

\section{STRUCTURE OF THE PRESENTATION}

It has already been stated above that the book is divided into three main parts. Part I deals with basic features of the Chinese economic system. It contains a contribution by Thomas Eger and Margot Schüller on 'A Comparison of Chinese and European-Style Federalism from a Law and Economics Perspective'. The second chapter in this part is by Pierre Garello and deals with 'The Road to Efficient Taxation in China'. The third chapter is by Jianwei Zhang and Yijia Jing dealing with 'Legal Pluralism in the Governance of Transitional China.'

Part II deals with specific aspects of the Chinese legal system from an economic perspective. Chapter 4, written by Roger Van den Bergh, deals with 'The Economics of Competition Policy and the Draft of the Chinese Competition Law'. Chapter 5, by Niels Philipsen addresses 'The Law and Economics of Professional Regulation. What Does the Theory Teach China?'. Anthony Ogus addresses 'Regulatory Arrangements and Incentives for Opportunistic Behaviour' in Chapter 6. Subsequently Chinese authors address specific aspects of the Chinese legal system. In Chapter 7, Julan Du, Lucy Liu Yajun and Sonia Wong deal with 'Special Treatment Firms and Administrative Governance of Capital Markets in China'. QingYun Jiang in Chapter 8 deals with 'Monitoring Problems versus Fiduciary Duties in Chinese Stock Companies'. Jian Wei and Shanguo Xue address in Chapter 9 'The Stable Self-Enforcement and Distribution of Property Right: The Right to Virtual Property in MMORPG'.

Part III contains contributions addressing 'China in the World Economy'. Chapter 10, by Anselm Kamperman Sanders, deals with 'Intellectual Property Law and Policy and Economic Development with Special Reference to China'. Chapter 11, by Michael G. Faure and Wang Hui, provides an 'Economic Analysis of Compensation for Oil Pollution Damage in China'.

Part IV consisting solely of Chapter 12 contains a set of concluding remarks by the editors. 


\section{CONTRIBUTORS}

The contributors to this book come, as was made clear, from various universities in Europe and in China. Michael Faure and Niels Philipsen are from Maastricht University. Wang Hui works at the Catholic University of Leuven. Anthony Ogus is affiliated to Maastricht University as well as Manchester University. Roger Van den Bergh works at the Rotterdam Institute for Law and Economics. Anselm Kamperman Sanders is affiliated to Maastricht University and with Macau as well. Pierre Garello works at the Université Paul Cézanne in Aix-en-Provence. Thomas Eger is from the Institute of Law and Economics at Hamburg University, whereas Margot Schüller works at the German Institute of Global and Area Studies (GIGA) - Institute of Asian Affairs in Hamburg. Jianwei Zhang and Yijia Jing are from Fudan University in Shanghai. Julan Du, Lucy Liu Yajun and Sonia Wong are from Hong Kong (Chinese University, Goldman Sachs and Lingnan University). Qing-Yun Jiang received a PhD from Hamburg University and currently works at the Law Faculty of Tongji University in Shanghai. Jian Wei and Shanguo Xue are affiliated to the Law and Economics Research Institute of Shandong University in Jinan.

A complete list of the contributors and their affiliation is provided after the table of contents.

\section{ACKNOWLEDGEMENTS}

As editors of this book, we are grateful to the many people who made this project possible. In this respect we refer both to the conference held in March 2006 at Fudan University in Shanghai and to the publication of the book. First of all, we would like to thank the Science Committee of the Law Faculty of Maastricht University and the German Research Foundation for financial support. In addition, we are grateful to Fudan University for providing financial support for the organization of the conference. We owe a special thanks to Katherine Walker and Sönke Häseler of Hamburg University who revised the English of some of the non-native English speakers. We are especially grateful to Henning Curti, Kid Schwarz, Alexander Schall, T. Somashekar and Peter Weise for providing useful comments on earlier versions of some of the contributions in this volume. We also owe thanks to the administrative centre of the Maastricht European Institute for Transnational Legal Research (METRO) and especially to Silvia Workum for editorial assistance in the preparation of the publication of this book. Finally, we are truly grateful for the - as usual - excellent and professional cooperation with the people 
working at Edward Elgar, our publisher, for all their assistance in the publication of this book.

The texts were finalized in September 2006, and for that reason developments after that date have not been treated.

Thomas Eger

Hamburg/Maastricht/Shanghai, September 2006

Michael Faure

Zhang Naigen 
Thomas Eger, Michael Faure, and Zhang Naigen - 9781847206978 Downloaded from PubFactory at 04/26/2023 07:12:59AM via free access 